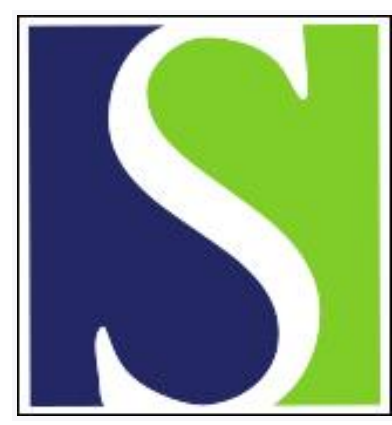

Scand J Work Environ Health 2000;26(2):118-130

https://doi.org/10.5271/sjweh.521

Issue date: Apr 2000

Body burden of aluminum in relation to central nervous system function among metal inert-gas welders

by Riihimäki V, Hänninen H, Akila R, Kovala T, Kuosma E, Paakkulainen $\mathrm{H}$, Valkonen S, Engström B

The following article refers to this text: 2008;34(6):451-462

Key terms: aluminum welding; neurophysiology; neuropsychology

This article in PubMed: www.ncbi.nlm.nih.gov/pubmed/10817377

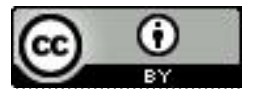




\title{
Body burden of aluminum in relation to central nervous system function among metal inert-gas welders
}

\author{
by Vesa Riihimäki, MD, ${ }^{1}$ Helena Hänninen, PhL, ${ }^{2}$ Ritva Akila, PhL, ${ }^{3}$ Tero Kovala, MD, ${ }^{5}$ Eeva Kuosma, \\ MSC, ${ }^{4}$ Harri Paakkulainen, MSc, ${ }^{4}$ Sinikka Valkonen, BSc(Eng), ${ }^{1}$ Bernt Engström, MSc ${ }^{6}$
}

\begin{abstract}
Riihimäki V, Hänninen H, Akila R, Kovala T, Kuosma E, Paakkulainen H, Valkonen S, Engström B. Body burden of aluminum in relation to central nervous system function among metal inert-gas welders. Scand $J$ Work Environ Health 2000:26(2):118-130.
\end{abstract}

\begin{abstract}
0bjectives The relationship between elevated internal aluminum loads and central nervous system function was studied among aluminum welders, and the threshold level for adverse effect was defined.

Methods For 65 aluminum welders and 25 current mild steel welders body burden was estimated, and the aluminum concentrations in serum (S-Al) and urine (U-Al) were analyzed with graphite furnace atomic absorption spectrometry with Zeeman background correction. Referents and low-exposure and high-exposure groups were defined according to an aggregated measure of aluminum body burden, the group median S-Al levels being 0.08 , 0.14 , and $0.46 \mu \mathrm{mol} / 1$, respectively, and the corresponding values for $\mathrm{U}-\mathrm{Al}$ being $0.4,1.8$, and $7.1 \mu \mathrm{mol} / \mathrm{l}$. Central nervous system functions were assessed with a neuropsychological test battery, symptom and mood questionnaires, a visual and quantitative analysis of electroencephalography (EEG), and P3 event-related potentials with pitch and duration paradigms.

Results Subjective symptoms showed exposure-related increases in fatigue, mild depression, and memory and concentration problems. Neuropsychological testing revealed a circumscribed effect of aluminum, mainly in tasks demanding complex attention and the processing of information in the working memory system and in the analysis and recall of abstract visual patterns. The visual EEG analysis revealed pathological findings only for aluminum welders. Mild, diffuse abnormalities were found in $17 \%$ of the low-exposure group and $27 \%$ of the high-exposure group, and mild to moderate epileptiform abnormalities at a frequency of $7 \%$ and $17 \%$, respectively.

Conclusions Both objective neurophysiological and neuropsychological measures and subjective symptomatology indicated mild but unequivocal findings dose-dependently associated with increased aluminum body burden. The study indicates that the body burden threshold for adverse effect approximates an U-Al value of $4-6 \mu \mathrm{mol} / \mathrm{l}$ and an $\mathrm{S}-\mathrm{A} 1$ value of $0.25-0.35 \mu \mathrm{mol} / 1$ among aluminum welders.
\end{abstract}

Key terms aluminum welding, neurophysiology, neuropsychology.

It is a paradox that the $3 \mathrm{rd}$ most abundant element of the Earth's crust, aluminum, is a toxicant for the central nervous system (CNS). A wealth of evidence from several animal species shows that aluminum salts administered centrally or peripherally induce neuropathological changes in the brain and spinal cord, neurobehavioral deficits, and seizures $(1,2)$. A characteristic subcellular change found in rabbit and cat brain is the formation of neurofibrillary tangles in neuronal cytoplasm (3). In humans, aluminum is associated with the so-called dialysis encephalopathy syndrome characterized by speech disturbances, seizures, and impaired cognitive function (4). Renal dialysis patients are at risk of aluminum accumulation in serum, bone tissue, and the brain, and the clinical picture of encephalopathy can emerge when the serum aluminum levels rise to $3-7 \mu \mathrm{mol} / 1$ or higher. Recently, 4 cases of irreversible encephalopathy were detected within 2 months of otoneurosurgery and bone reconstruction with aluminum-containing bone cement $(5$, $6)$. The aluminum concentration in the cerebrospinal fluid

1 Department of Industrial Hygiene and Toxicology, Finnish Institute of Occupational Health, Helsinki, Finland.

2 Helsinki, Finland.

3 Department of Occupational Medicine, Finnish Institute of Occupational Health, Helsinki, Finland.

4 Department of Epidemiology and Biostatistics, Finnish Institute of Occupational Health, Helsinki, Finland.

5 Department of Clinical Neurophysiology, Helsinki University Central Hospital, Helsinki, Finland.

6 Turku Regional Institute of Occupational Health, Turku, Finland.

Reprint requests to: Dr Vesa Riihimäki, Department of Industrial Hygiene and Toxicology, Finnish Institute of Occupational Health, Topeliuksenkatu 41 aA, FIN-00250 Helsinki, Finland. [Email: vesa.riihimaki@occuphealth.fi] 
(CSF) of these patients was increased by about 100 -fold due to a postoperative CSF fistula and leaching of aluminum from the biomaterial.

Some epidemiologic observations suggest that environmental exposure to aluminum via drinking water may be a risk factor for Alzheimer's disease (7-12). Among the population at large only a slight accumulation of aluminum body burden occurs with increasing age due to intake from various sources, the major potential source being aluminum-containing pharmaceuticals $(13,14)$. Although the limited intake of aluminum specifically from water and the normally low absorption of aluminum from the intestine, coupled with ready excretion via the kidneys, reduce the biological plausibility that environmental aluminum is a hazard for the general population, the issues relevant for resolving the debate on aluminum and Alzheimer's disease have recently been highlighted (15).

Occupational exposures during the primary smelting of aluminum (16), foundry work $(17,18)$, production of aluminum flake powder (19), or the welding of aluminum with the metal inert-gas (MIG) method (20-22) can be associated with an increased uptake of aluminum. While humans are mostly protected against excessive uptake from the gastrointestinal tract, there appears to be no similar mechanism of protection against respirable, sparingly soluble aluminum particles which are trapped in the lungs and subsequently slowly released systemically. However, few studies have so far explored the potential of occupational aluminum exposure causing nervous system toxicity. The production of aluminum flake powder may have involved massive exposure to respirable aluminum particles (23). In 1 case report, a worker developed irreversible encephalopathy which resembled the dialysis encephalopathy syndrome; the brain aluminum concentration was 10 times higher than normally (24). In another case, a 78-year-old former flake powder worker who had a previous diagnosis of aluminosis was found to be moderately demented with motor disturbances, and he exhibited a high aluminum concentration in his CSF (25). There are reports of impaired cognitive or psychomotor functions, emotional instability, and depression among aluminum foundry workers (17), primary aluminum production (potroom) workers $(26,27)$, and miners exposed to particulate aluminum, purported to be a prophylactic against silicosis (28). Aluminum workers were not overrepresented among the nearly 200 patients of Alzheimer's disease in a case-referent study (29).

Welders of aluminum are an important target group for research on aluminum toxicity because these skilled metal workers constitute a large population and because MIG welding generates aluminum oxide fumes. Longterm aluminum welders reported concentration difficulties and depression twice as frequently as welders of mild steel (30). We have previously conducted a study on a small group of rather homogeneously exposed MIG welders who had moderately increased serum and urinary aluminum levels, and we found an internal load-related slight impairment of memory functions, learning, and attention and also some characteristic electroencephalographic (EEG) changes (31). Since the study group was small, the findings were only suggestive. A larger and more powerful study has subsequently been conducted to confirm the previous findings and to examine the doseresponse for adverse effect. The methods were chosen to ensure comparability with our earlier results; however, a refined selection of neuropsychological tests was employed to examine the hypothesis that memory and attention were the functions most sensitive to aluminum toxicity.

\section{Subjects and methods}

\section{Identification of the study population}

A nationwide survey identified 10 companies which had been welding aluminum for many years using the MIG method. After the study protocol was approved by the Ethics Committee of the Finnish Institute of Occupational Health, the companies and their occupational health services were contacted, and they agreed to collaborate in the study. Subsequently, site visits were made to ensure that the welders currently had no potentially confounding exposures (such as solvents), and a meeting was arranged to inform the prospective subjects about all aspects of the study. Eight of the companies were small, each employing only a handful of welders who had solely worked on aluminum for many years; the entire work force of these companies volunteered for the study. Two companies were larger, employing both aluminum and mildsteel welders. The occupational health nurses contacted potential candidates, both the current long-term aluminum welders and the referent mild-steel welders matched for age and gender. Only a few workers refused to participate. In all, 65 active aluminum welders ( 62 men and 3 women) and 25 active welders of mild steel (all men) volunteered.

\section{Examinations}

Two-thirds of the subjects employed by the 9 participating companies were examined at the Finnish Institute of Occupational Health. All those who had to commute longer distances were accommodated overnight to ensure sufficient rest before the examinations. The biggest participating company (a shipyard) had an occupational health center, and their employees (11 aluminum welders and 20 referents) were examined on the company premises. All the subjects gave their written, informed consent. The examination started with a semistructural interview for data on occupational history, education, 
previous or present symptoms, illnesses and injuries, use of drugs and alcohol, and smoking habits. The inquiry targeted the nervous system and general health, and it was conducted by a neurophysiologist. Thereafter, inquiries for symptoms and mood states and neuropsychological testing were conducted by a well-trained psychologist, who was unaware of the exposure status of the subjects. After a lunch break, the subjects underwent neurophysiological examinations.

\section{Symptom inquiries}

Disturbances of subjective well-being were assessed by a symptom questionnaire, and by the Finnish version of the Profile of Mood States (POMS). The symptom questionnaire inquires about symptoms experienced during the past year. It consists of 6 symptom scales: sleeping disturbances ( 3 items), fatigue ( 5 items), memory and concentration difficulties ( 4 items), emotional lability $(6$ items), somatic complaints (5 items), and sensory and motor symptoms ( 8 items). Three alternatives are given for an answer for each item: never, sometimes, often. The respective scores are 0,1 , and 3 , and the scale sum is the sum total of the item scores of the scale in question. POMS comprises 38 adjectives to inquire about feelings and moods during the past 7 days. The scales yielded by our POMS version were tension, hostility, depression, fatigue, vigor, and forgetfulness. The scales of both inquiries are based on factor analysis of previous unpublished research data on occupational samples.

\section{Neuropsychological test methods}

The test battery with 12 tests used in our previous aluminum study (31) was complemented by a more comprehensive selection of tests for attention and memory. Table 1 shows the methods used in this study.
The Stroop task was a version of 6 colors and 84 items. Two conditions, those of color naming and color words were used.

In Bourdon-Wiersma (BW) dot cancellation there is a paper sheet containing 25 rows of dots, each row containing 9 groups of 3,8 groups of 4 , and 8 groups of 5 dots. The task is to cancel all groups of 4 dots for 4 minutes. The variables were for speed (BW speed) and accuracy (BW accuracy). In the counting task the subjects counted backwards for 1 minute, starting from 196. The dual-task test comprises simultaneous dot cancellation and counting backwards for 2 minutes. The variables were speed for both cancellation (D-T cancellation speed) and counting (D-T counting speed).

The synonyms task consists of 35 items. One item contains 6 words: a well-known target word and 5 other words, one of which has the closest equivalent to the target. The subject's task is to choose the right alternatives in 6 minutes. The time limit was based on our ongoing study with unexposed welders, where $90 \%$ of the subjects completed at least $90 \%$ of the task.

Incidental learning was measured with 2 subtests of the Wechsler Adult Intellegence Scale (WAIS). After completing the similarities test, the subjects were asked both free and cued recall of the items, the latter task being presented as a paired associate test. After completing the digit symbol test, the subjects were asked to place the right symbols in blank squares below the numbers $1-9$.

In the homogeneous interference test the subjects were asked to repeat 2 sets of 3 isolated 2-syllable words. After the repetition, the subjects were asked to recall the first set, then the second set. Four trials with different sets of words were administered. In all, 24 different words were used.

Memory for designs is a modification of the test developed by Graham \& Kendall (33). It contains 10

Table 1. Main cognitive domains explored in the study and the neuropsychological tests used for the assessment.

\begin{tabular}{|c|c|c|c|}
\hline Main cognitive domain & Neuropsychological test & Number of variables & Reference \\
\hline \multirow[t]{2}{*}{ Psychomotor function } & Finger tapping ${ }^{a}$ & 1 & Gamberale et al, 1989 (32) \\
\hline & Santa Ana dexterity test ${ }^{a}$ & 1 & Hänninen \& Lindström, 1989 (33) \\
\hline Reaction time & Simple visual reaction time ${ }^{\mathrm{a}}$ & 1 & Gamberale et al, 1989 (32) \\
\hline \multirow[t]{6}{*}{ Attention } & Digit span (forward and reversed) ${ }^{\mathrm{a}}$ & 2 & Wechsler, 1992 (34) \\
\hline & Digit symbola & 1 & Wechsler, 1971 (35) \\
\hline & Stroop color-word & 2 & Stroop, $1935(36)$ \\
\hline & Bourdon-Wiersma cancellation test & 3 & Hänninen \& Lindström, 1989 (33) \\
\hline & Counting backwards & 1 & \\
\hline & Dual task & 2 & Vilkki et al, 1996 (37) \\
\hline \multirow[t]{2}{*}{ Verbal abilities } & Similarities & $\overline{1}$ & Wechsler, 1971 (35) \\
\hline & Synonyms ${ }^{\mathrm{a}}$ & 1 & Hänninen \& Lindström, 1989 (33) \\
\hline \multirow{2}{*}{ Visual or visuospatial abilities } & Embedded figures ${ }^{a}$ & 1 & Valciukas \& Singer, 1979 (38) \\
\hline & Block designa & 1 & Wechsler, 1971 (35) \\
\hline \multirow[t]{5}{*}{ Memory and learning } & Associative learning (verbal) ${ }^{\mathrm{a}}$ & 1 & Wechsler, 1986 (39) \\
\hline & Recall of similarities & 2 & Lezak, $1995(40)$ \\
\hline & Recall of digit symbo|a & 1 & Lezak, 1995 (40) \\
\hline & Homogenous interference & 1 & Christensen, 1974 (41) \\
\hline & Memory for designs ${ }^{a}$ & 1 & Hänninen \& Lindström, 1989 (33) \\
\hline
\end{tabular}

a Test employed in our previous aluminum study (Hänninen et al 1994). 
geometric designs. The subject is asked to draw a design immediately after a 5 -second presentation. To perform the task, visuospatial analysis is needed, and verbal labeling of the stimuli is difficult.

The psychological test procedure was carried out in a strictly standardized manner. Two psychologists (authors HH and RA) scored the tests blindly and independently. In the few cases where discrepancy in primary scoring occurred, consensus was easily obtained.

\section{Neurophysiological methods}

Quantitative electroencephalography (QEEG) was recorded in a quiet and dim room. The subjects sat in an armchair, kept their eyes closed, and were reminded to stay awake. Surface electrodes were attached to the scalp according to the international $10-20$ system. Two additional electrodes were used: an Fpz electrode (between $\mathrm{Fp} 1$ and Fp2 electrodes) and an Oz electrode (between electrodes $\mathrm{O} 1$ and $\mathrm{O} 2$ ). The recording was performed with Cadwell spectrum 32 equipment. Electroencephalography (EEG) was recorded with 21 channels. The signal was filtered using a 70- $\mathrm{Hz}$ low-pass filter, and, in addition, a $50-\mathrm{Hz}$ notch filter was used. The visual interpretation, choice of epochs and quantitative analyses were performed off-line with a Cadwell RDC-32 reading station. For the quantitative analysis, 24 epochs lasting 2.5 seconds each were gathered ( 1 minute). The epochs chosen had to be artifact-free and without signs of a lowered level of vigilance in the EEG or electrooculographic (EOG) channels during the recording. Quantitative analyses were made within the $1.5-25 \mathrm{~Hz}$ frequency band using the neurometrics program of the Cadwell RDC-32 equipment. The analyzed frequency band was divided into the delta $(1.5-3.5 \mathrm{~Hz})$, theta $(3.5-7.5 \mathrm{~Hz})$, alpha $(7.5-12.5 \mathrm{~Hz})$, and beta $(12.5-25.0 \mathrm{~Hz})$ bands. In monopolar montages (A1A2 as reference), absolute and relative power values were analyzed in the aforementioned bands in all 21 channels. The mean frequencies within the whole $1.5-25 \mathrm{~Hz}$ frequency band was analyzed for all channels. The number of variables was reduced by calculating the regional means from the original variables: frontal region (Fp1, Fp2, Fpz, F3, F4, Fz), temporal region (T3, T4, T5, T6), centroparietal region (C3, C4, Cz, P3, P4, Pz), and occipital region (O1, O2, $\mathrm{Oz}$ ). After the calculations there were $36 \mathrm{EEG}$ variables (16 for the absolute power, 16 for the relative power, and 4 for mean frequencies).

The EEG recordings were interpreted visually using a structured form. One of the authors (TK) read all the recordings while unaware of the exposure status of the subjects.

The P3 event-related potentials (P3 ERP) were studied with 2 paradigms. In pitch-P3 ERP, the target sound stimuli differed from the standard sounds by their pitch.
In duration-P3 ERP, the targets differed from the standards by their duration. Pitch-P3 ERP were recorded for all subjects, and duration-P3 ERPs were recorded for the subjects studied at the Finnish Institute of Occupational Health.

Pitch-P3 was examined while the subjects were awake, their eyes were closed, and they were sitting in a comfortable chair. Tones were presented binaurally at a $70-\mathrm{dB}$ sound pressure level with a $10-\mathrm{ms}$ rise time, a 30 ms plateau time, and a $10-\mathrm{ms}$ fall time. The stimulation frequency was $0.50-0.58 \mathrm{~Hz}$. The standard tone frequency was $1000 \mathrm{~Hz}$, and the target tone frequency was $2000 \mathrm{~Hz}$. Two 256-trial blocks were presented, each containing $64(25 \%)$ target stimuli in a random order. The subjects were instructed to count silently the number of the $2-\mathrm{kHz}$ targets. Activity was recorded at the $\mathrm{Cz}$ and $\mathrm{Pz}$ electrode sites of the 10-20 International System, referred to linked earlobes, and with periorbital electrodes to monitor eye movements and blinks. All the electrodes were affixed with electrode paste and had an impedance of $<10 \mathrm{k} \Omega$. The filter bandpass was $0.5-70 \mathrm{~Hz}$. The analysis time was $650 \mathrm{~ms}$, including a $50-\mathrm{ms}$ prestimulus base line. Wave forms were averaged online by a commercial apparatus (Cadwell Spectrum 32), which also controlled the stimulus presentation. Trials containing activity exceeding $\pm 80 \mu \mathrm{V}$ were automatically rejected. The latencies and amplitudes were measured afterwards. At first, the mean responses were formed from the 2 original responses in the $\mathrm{Pz}$ channel. The mean responses were then filtered digitally $(6-\mathrm{Hz}$ low-pass filter). The latencies and amplitudes were measured from the filtered mean responses. In the amplitude measurements, the prestimulus base line was used as the reference level. The findings of the pitch-P3 ERP were classified as normal or abnormal in a comparison with reference values of the laboratory of clinical neurophysiology of the Finnish Institute of Occpational Health. These reference values were derived from a population of 85 subjects [ 14 men and 71 women, age 20-63 (mean 41.1, SD 10.2) years]. The normal limits were age-dependent and were calculated using a linear regression analysis, the mean +2 SD line being used in the interpretation of the latencies and mean -2 SD line being used for the amplitudes.

The subjects kept their eyes open during the durationP3 ERP recording, and looked at a fixation point. The tone frequency for both the standards and targets was $1000 \mathrm{~Hz}$. The duration of standard stimuli was $60 \mathrm{~ms}$ (a 5-ms rise time, a 50-ms plateau time, and a 5 -ms fall time), and the duration of target stimuli was $100 \mathrm{~ms}$ (a 5-ms rise time, a 90-ms plateau time, and a 5 -ms fall time). Two 300-trial blocks were presented, each containing $60(20 \%)$ target stimuli in a random order. In other respects, the methods were similar to those used for recording the pitch-P3 ERP. 


\section{Determination of exposure}

In addition to an inquiry for the full occupational history, including an estimation of the total duration of welding with aluminum, the body burden of aluminum was determined from measurements of the serum $(\mathrm{S}-\mathrm{Al})$ and urinary $(\mathrm{U}-\mathrm{Al})$ aluminum concentrations. The aluminum levels in these samples were deemed the primary marker of biologically relevant exposure because of the known cumulative characteristics of the metal when inhaled as a welding fume. However, according to our previous observations with aluminum welders (manuscript in preparation), it is important to make a distinction between concentrations related to contemporary aluminum uptake and that related to the long-term body burden. As the latter was considered more relevant, urine samples were collected after an exposure-free interval of 2 days (on Monday morning), while serum samples were drawn on the morning of the examination day. Moreover, the blood lead concentration was measured to exclude a possible confounder.

Aluminum was determined in the serum and urine samples using graphite furnace atomic absorption spectrometry (GFAAS) with Zeeman background correction, and the $\mathrm{U}-\mathrm{Al}$ concentrations were corrected to a relative density of 1.024 (42). The method is based on platform atomization in pyrolytically coated graphite tubes after 4-fold dilution with nitric acid. For the serum analysis, the matrix-matched standard curve was prepared, and for urine the method of standard additions was used. The within-run imprecision (CV) for serum and urine was 3\% and $5 \%$, respectively, and the between-day imprecision was $6 \%$ and $7.2 \%$, respectively, at a concentration level of $4.0 \mu \mathrm{mol} / 1$. The between-day imprecision for $\mathrm{U}-\mathrm{Al}$ was $15.7 \%$ at a concentration level of $0.24 \mu \mathrm{mol} / \mathrm{l}$. The detection limits were $0.02 \mu \mathrm{mol} / 1$ for serum and $0.07 \mu \mathrm{mol} /$ 1 for urine. The laboratory is a regular participant of the
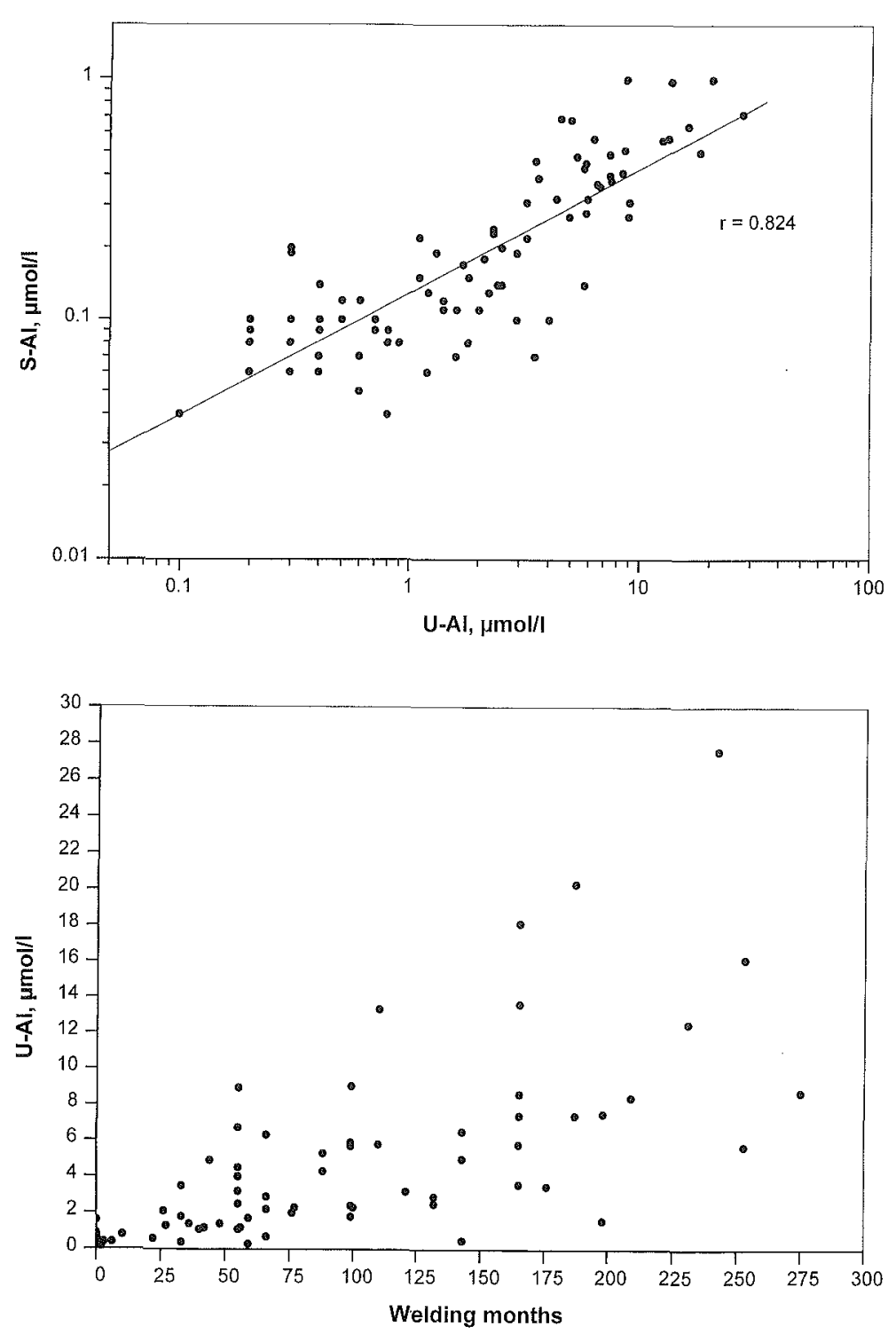

Figure 1. Correlation of the serum (S-Al) and urinary (U-AI) aluminum concentrations of the study population of 84 welders.
Figure 2. Correlation between the duration of welding history with aluminum (months) and urinary aluminum concentration in a morning sample voided after an interval of 2 days away from exposure $(\mathrm{N}=84)$. 
Trace Elements Quality Assessment Scheme (University of Surrey, Guildford, United Kingdom) for S-Al, and it achieved the maximum cumulative performance score during the preceding year. For $\mathrm{U}-\mathrm{Al}$, a certificate in the external quality control scheme of the German Society of Occupational Medicine has been obtained.

\section{Exposure status and designation of study groups}

In the population of aluminum MIG welders, the S-Al ranged from 0.06 to $1.0 \mu \mathrm{mol} / 1$, and the $\mathrm{U}$-Al ranged from 0.3 to $27.6 \mu \mathrm{mol} / \mathrm{l}$. Among the current mild-steel welders, the corresponding ranges were $0.04-0.19 \mu \mathrm{mol} / 1$ and $0.1-1.6 \mu \mathrm{mol} / 1$, respectively. For $1 / 3$ of the aluminum welders, the exposure had continued over 10 years with a maximum of 23 years. Even several of the current mild-steel welders had had some past experience welding with aluminum. The S-Al and U-Al measurements correlated fairly well in the study population (figure 1), and both of them correlated with the total duration of welding with aluminum. (Only U-Al versus exposure duration is shown in figure 2.)

Because some MIG welders did not have significantly increased body burdens, whereas some of the current mild-steel welders did (including one with no past history of aluminum welding), it was decided to form the groups according to the measured internal aluminum load. To compose an aggregated measure of aluminum body burden, we constructed similar distribution patterns for both $\mathrm{S}-\mathrm{Al}$ and $\mathrm{U}-\mathrm{Al}$ (table 2) and then summed the 2 individual scores (A1-sum). It was hypothesized that, by this method, the individual body burden could be characterized with higher accuracy. The referents were workers with $\mathrm{Al}$-sum scores of 2 or 3 . The low-exposure group was comprised of workers with Al-sum scores of 4-8, and the high-exposure group had Al-sum scores of 918.

Among the 90 workers studied, 3 persons were excluded because of clinically recognized neurological findings and confounding exposure. In the psychological analyses, the final number of eligible subjects was 82 ( 79 men and 3 women) after the further exclusion of 5 subjects ( 1 immigrant with poor language skills and 4 persons with either a low or high primary cognitive or educational level). Four additional subjects were not included in some of the analyses because of incomplete data. The neurophysiological analyses included 84 subjects ( 81 men and 3 women) as 3 EEG recordings were not technically acceptable. The division into subgroups by the Al-sum gave 25 referents, 29 welders with low exposure, and 30 welders with high exposure. The age and exposure characteristics of the study groups are shown in table 3.

\section{Confounding factors}

Age was a potential confounding factor (table 3), and it was controlled in the statistical analyses. According to the thorough semistructured interview, in terms of ethnic and cultural background, education, social status, occupation, and the main job characteristics, the final study population was homogeneous. There were no heavy drinkers or users of psychotropic drugs. The social consumption of alcohol did not differ between the groups. There was no long-lasting or recent use of aluminumcontaining antacids. Blood lead was analyzed and was not considered of any consequence $(<0.4 \mu \mathrm{mol} / 1)$.

\section{Statistical methods}

SAS (Statistical Analysis System) programs were used in the statistical analyses. The associations of the symptom scales, mood scales, and psychological tests with the exposure variables were examined by the partial correlation with adjustment for age. The neurophysiological variables had skewed distributions, and their correlations

Table 2. Method of scoring the urinary aluminum (U-Al) and serum aluminum (S-Al) concentration for the calculation of their sum (Al-sum). ${ }^{\text {a }}$

\begin{tabular}{lrrr|cccc}
\hline $\begin{array}{l}\text { U-Al } \\
(\mu \mathrm{mol} / \mathrm{I})\end{array}$ & $N$ & $\begin{array}{r}\text { Score Cumulative } \\
\text { distribution }\end{array}$ & $\begin{array}{c}\text { S-Al } \\
(\mu \mathrm{mol} / \mathrm{l})\end{array}$ & $\mathrm{N}$ & Score & $\begin{array}{c}\text { Cumulative } \\
\text { distribution }\end{array}$ \\
\hline $0.1-0.6$ & 21 & 1 & 21 & $0.04-0.09$ & 21 & 1 & 21 \\
$0.7-1.4$ & 14 & 2 & 35 & $0.10-0.13$ & 16 & 2 & 37 \\
$1.5-2.4$ & 11 & 3 & 46 & $0.14-0.18$ & 8 & 3 & 45 \\
$2.5-3.9$ & 9 & 4 & 55 & $0.19-0.25$ & 9 & 4 & 54 \\
$4.0-5.9$ & 11 & 5 & 66 & $0.26-0.35$ & 7 & 5 & 61 \\
$6.0-7.9$ & 6 & 6 & 72 & $0.36-0.45$ & 8 & 6 & 69 \\
$8.0-9.9$ & 5 & 7 & 77 & $0.46-0.60$ & 8 & 7 & 77 \\
$10.0-19.9$ & 5 & 8 & 82 & $0.61-0.80$ & 4 & 8 & 81 \\
$20.0-27.6$ & 2 & 9 & 84 & $0.81-1.0$ & 3 & 9 & 84 \\
\hline
\end{tabular}

a To compose an aggregated measure of aluminum body burden, we constructed similar distribution patterns for both serum and urinary aluminum and then added the 2 individual scores together (Al-sum)

Table 3. Age and exposure data for 3 welder groups formed on the basis of indices of aluminum body burden.

\begin{tabular}{|c|c|c|c|c|c|c|c|c|c|c|c|c|c|c|}
\hline \multirow[t]{2}{*}{ Group } & \multicolumn{3}{|c|}{ Age (years) } & \multicolumn{3}{|c|}{$\begin{array}{l}\text { Al-suma } \\
\text { (umol/I) }\end{array}$} & \multicolumn{3}{|c|}{$\begin{array}{l}\text { Serum aluminum } \\
(\mu \mathrm{mol} / 1)\end{array}$} & \multicolumn{3}{|c|}{$\begin{array}{l}\text { Urine aluminum } \\
\text { (months) }\end{array}$} & \multicolumn{2}{|c|}{ Aluminum welding } \\
\hline & Mean & Median & Range & Mean & Median & Range & Mean & Median & Range & Mean & Median & Range & Mean Median & in Range \\
\hline $\begin{array}{l}\text { Referents }(\mathrm{N}=25) \\
\text { Low exposure }(\mathrm{N}=29) \\
\text { High exposure }(\mathrm{N}=30)\end{array}$ & $\begin{array}{l}38.1 \\
36.1 \\
42.0\end{array}$ & $\begin{array}{l}37.4 \\
35.7 \\
43.9\end{array}$ & $\begin{array}{l}29-48 \\
24-54 \\
22-58\end{array}$ & $\begin{array}{r}2.6 \\
5.7 \\
12.8\end{array}$ & $\begin{array}{r}3 \\
6 \\
12\end{array}$ & $\begin{array}{l}2-3 \\
4-8 \\
9-18\end{array}$ & $\begin{array}{l}0.08 \\
0.15 \\
0.50\end{array}$ & $\begin{array}{l}0.08 \\
0.14 \\
0.46\end{array}$ & $\begin{array}{l}0.04-0.12 \\
0.07-0.24 \\
0.27-1.00\end{array}$ & $\begin{array}{l}0.5 \\
2.0 \\
8.8\end{array}$ & $\begin{array}{l}0.4 \\
1.8 \\
7.1\end{array}$ & $\begin{array}{l}0.1-1.2 \\
0.3-5.7 \\
3.2-27.6\end{array}$ & 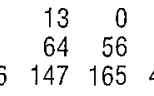 & $\begin{array}{r}0-143 \\
0-198 \\
44-275\end{array}$ \\
\hline
\end{tabular}

To compose an aggregated measure of aluminum body burden, we constructed similar distribution patterns for both serum and urinary aluminum and then added the 2 individual scores together (Al-Sum). 
Table 4. Means and standard errors (SE) of the means of 4 symptom scales in the 3 welder groups and the age-adjusted P-values from the covariance analysis.

\begin{tabular}{|c|c|c|c|c|c|c|c|c|}
\hline \multirow[t]{3}{*}{ Group } & \multicolumn{8}{|c|}{ Symptom scale } \\
\hline & \multicolumn{2}{|c|}{ Fatigue } & \multicolumn{2}{|c|}{$\begin{array}{l}\text { Memory and } \\
\text { concentration difficulties }\end{array}$} & \multicolumn{2}{|c|}{ Emotional lability } & \multicolumn{2}{|c|}{$\begin{array}{l}\text { Sensory and } \\
\text { motor symptoms }\end{array}$} \\
\hline & Mean & SE & Mean & SE & Mean & SE & Mean & SE \\
\hline Referents ( $N=25)$ & 2.12 & 0.25 & 1.80 & 0.17 & 1.36 & 0.25 & 1.16 & 0.35 \\
\hline Low exposure $(\mathrm{N}=28)$ & 2.07 & 0.35 & 2.21 & 0.39 & 1.93 & 0.45 & 1.25 & 0.42 \\
\hline High exposure $(\mathrm{N}=29)$ & 4.00 & 0.63 & 3.90 & 0.48 & 2.93 & 0.53 & 2.62 & 0.51 \\
\hline
\end{tabular}

aifference between the referents and the high-exposure group: fatigue $P=0.027$, memory and concentration difficulties $P=0.004$, emotional lability

$P=0.045$, sensory and motor symptoms $P=0.109$.

Table 5. Prevalence of individual symptoms in the 3 welder groups.

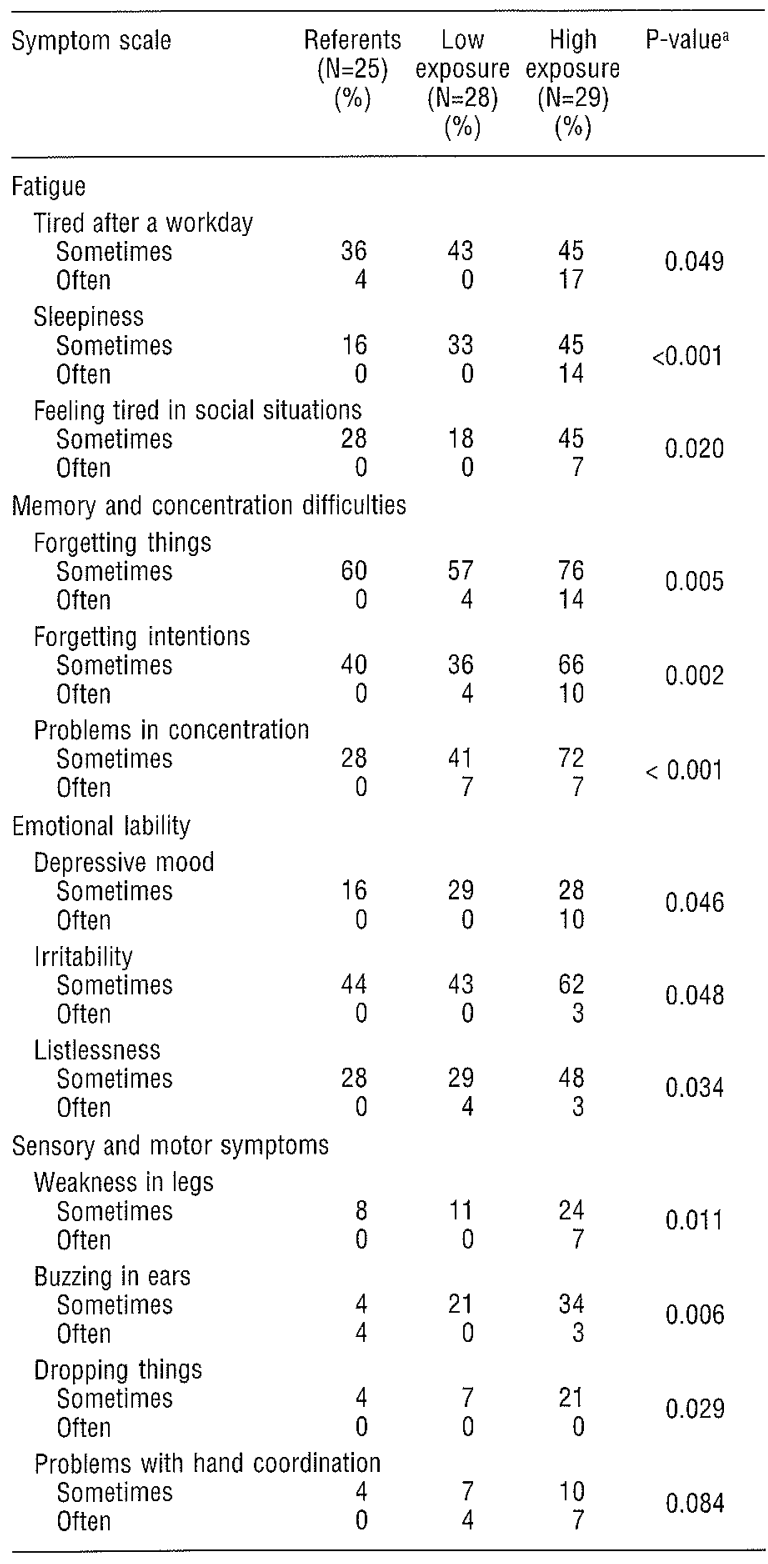

a Significance tested with the exact test of trend were examined by Spearman's partial rank-order correlations.

For the group differences in symptom scales, POMS scales, and tests, covariance analyses with age as the covariate were performed to test the overall differences of all the effect measures and to separate the effects of age and aluminum. We used Tukey-Kramer's multiple comparison method [43, 44 and an unpublished manuscript (Tukey JW. The problem of multiple comparisons, 1953)] to test pairwise differences of the means of the 3 exposure groups. The Cochran-Armitage exact test for trend (45-47) was applied for the individual symptoms and for neurophysiological findings. All the tests were one-sided, except for the two-sided analysis of QEEG.

\section{Results}

\section{Subjective symptoms and emotional status}

The associations between the POMS scales and the various exposure measures were not statistically significant. A comparison of the symptom scales resulted in 3 groups by covariance analysis, with age as a covariate, indicated significant differences between the high-exposure group and the referents for 3 scales. The group means and the age-adjusted $\mathbf{P}$-values are given in table 4 . The biggest difference was found in memory and concentration difficulties, and a more moderate difference was found for fatigue and emotional lability. For sleeping disturbances and sensory and motor symptoms the difference was not significant.

Table 5 shows the symptoms that differed the most between the groups. Thirteen of the 31 questionnaire items showed at least a marginally significant difference among the groups. Of the items for fatigue, sleepiness had the strongest connection with the exposure. Tiredness after a workday and feeling tired in social situations showed a more moderate increase. Feelings of drowsiness in the mornings and falling asleep in front of the television showed no trend with exposure. In the scale 
for memory and concentration problems, the questions "Do you have difficulties in concentration?", "Do you easily forget what you intended to do or to say?", and "Do you forget things" showed highly significant group differences, whereas general absent-mindedness showed no trend with exposure at all. Of the 6 items for emotional lability, there was a moderate increase in depressive mood, irritability, and listlessness. No relation was suggested for restlessness, fearfulness, and sudden mood changes. Concerning sensory and motor symptoms, subjective weakness of the legs, buzzing in the ears, dropping things, and, more marginally, problems with hand coordination increased with exposure. No relation with aluminum was found for weakness or tremor in the upper limbs, difficulty walking in the dark, or blurriness of lines while reading.

The age-adjusted correlations between the symptom scales and 4 exposure indices are given in table 6 . The symptoms were more related to Al-sum than to S-Al or $\mathrm{U}-\mathrm{Al}$. The strongest associations were, however, with the exposure time (Al-months). The scale for sensory and motor symptoms had only a marginal correlation with Alsum and S-Al.

\section{Neuropsychological findings}

A comparison of the test results of the 3 groups by covariance analysis, with age as a covariate, indicated 6 significant differences between the high-exposure and reference group (table 7). Exposure-related impairments of the results were found in accuracy in the B-W cancellation task, backwards counting, both components of the dual-task, synonyms, and memory for designs tests $(\mathrm{P}<0.05$ for all). The scores of the vistospatial and constructive task (block design) showed a tendency, though not significant, towards impairment. Performance of digit span forward tended to improve with exposure.

Significant age-adjusted correlations between the test variables and exposure indices are shown in table 8 . The results of memory for designs and block design did not correlate with any of the exposure indices. The test performance seemed to be somewhat more associated with
$\mathrm{U}-\mathrm{Al}$ than with $\mathrm{S}-\mathrm{Al}$, and it was the most consistently associated with Al-sum.

\section{Neurophysiological findings}

Quantitative electroencephlography. U-Al correlated positively with the relative power in the delta and theta bands and negatively with the relative power in the alpha band. None of the correlation coefficients reached statistical significance, however. The strongest associations were observed between $\mathrm{U}-\mathrm{Al}$ and frontal relative delta power $(r=0.22, P=0.053)$, as well as frontal relative alpha power $(\mathrm{r}=-0.21, \mathrm{P}=0.060)$. No statistically significant differences were observed between the subgroups in the analysis of covariance with age as a covariate.

Visual electroencephlography. As shown in table 9, nonspecific, diffuse EEG abnormalities were observed in 13 subjects. All of them had mild abnormalities. Five of them belonged to the low-exposure group, 8 belonged to the high-exposure group, and the exposure-related linear trend of change among the groups was significant. Eleven subjects had a diffuse, arrhythmic slow activity in their EEG; among them 10 had generalized bursts of delta-theta activity, and 1 subject had an abnormally slow posterior basic rhythm. Epileptiform abnormalities were observed in 7 subjects (table 9). The degree of abnormality was mild in 6 subjects and moderate in 1 subject. Two of the subjects belonged to the low-exposure group, while 5 subjects had had high levels of exposure, the trend

Table 6. Symptom scales showing significant correlations after adjustment for age with one or more of the exposure indices. (Al-sum $=$ sum of serum aluminum and urinary aluminum , S-Al = serum aluminum, $\mathrm{U}-\mathrm{Al}=$ urinary aluminum, $\mathrm{Al}-$-months $=$ months of aluminum welding)

\begin{tabular}{llllll}
\hline Symptom scale & Al-sum & S-Al & U-Al & Al-months \\
\hline Fatigue & $0.27^{* *}$ & $0.22^{*}$ & 0.16 & $0.38^{* * *}$ \\
Memory and concentration difficulties & $0.29^{* *}$ & 0.15 & $0.24^{*}$ & $0.32^{* *}$ \\
Emotional lability & $0.22^{*}$ & 0.10 & 0.17 & $0.31^{* *}$ \\
Sensory and motor symptoms & $0.21^{*}$ & $0.21^{*}$ & 0.13 & 0.17 \\
\hline
\end{tabular}

${ }^{*} P<0.05,{ }^{* *} P<0.01,{ }^{* * *} P<0.001$.

Table 7. Means and standard errors (SE) of the means of the test variables for the 3 welder groups and the age-adjusted P-values from the covariance analysis. (NS = not significant)

\begin{tabular}{|c|c|c|c|c|c|c|c|c|c|c|c|c|c|c|c|c|}
\hline \multirow[t]{2}{*}{ Group } & \multicolumn{2}{|c|}{$\begin{array}{l}\text { Digit span } \\
\text { forward }\end{array}$} & \multicolumn{2}{|c|}{$\begin{array}{l}\text { Digit } \\
\text { symbol }\end{array}$} & \multicolumn{2}{|c|}{$\begin{array}{c}\text { Bourdon-Wiersma } \\
\text { dot cancellation } \\
\text { accuracya }\end{array}$} & \multicolumn{2}{|c|}{$\begin{array}{l}\text { Counting } \\
\text { backwards }\end{array}$} & \multicolumn{2}{|c|}{$\begin{array}{l}\text { Dual-task } \\
\text { cancellation } \\
\text { speed }\end{array}$} & \multicolumn{2}{|c|}{$\begin{array}{l}\text { Dual-task } \\
\text { counting } \\
\text { speed }\end{array}$} & \multicolumn{2}{|c|}{ Synonyms } & \multicolumn{2}{|c|}{$\begin{array}{l}\text { Memory } \\
\text { for designs }\end{array}$} \\
\hline & Mean & SE & Mean & $S E$ & Mean & SE & Mean & SE & Mean & SE & Mean & SE & Mean & SE & Mean & SE \\
\hline Referents $(\mathrm{N}=25)$ & 5.56 & 0.31 & 51.1 & 1.86 & 4.24 & 0.67 & 53.9 & 2.41 & 50.3 & 1.90 & 56.6 & 3.84 & 29.4 & 0.90 & 18.6 & 0.31 \\
\hline Low exposure $(\mathrm{N}=28)$ & 6.36 & 0.35 & 50.9 & 1.93 & 4.39 & 0.64 & 50.7 & 2.10 & 47.4 & 1.72 & 51.8 & 2.85 & 28.3 & 0.89 & 17.7 & 0.45 \\
\hline High exposure $(N=29)$ & 6.41 & 0.39 & 44.6 & 1.91 & 7.14 & 1.21 & 44.6 & 2.24 & 42.8 & 2.24 & 42.8 & 2.53 & 25.7 & 1.10 & 17.2 & 0.32 \\
\hline Age-adjusted P-value & NS & & 0.128 & & 0.0497 & & 0.042 & & 0.047 & & 0.021 & & 0.011 & & 0.030 & \\
\hline
\end{tabular}

a Lower value indicates better performance

b Difference between the referents and the high-exposure group. 
Table 8. Age-adjusted correlations between the exposure indices and 7 neuropsychological test variables. (Al-Sum = sum of serum aluminum and urinary aluminum, $\mathrm{S}-\mathrm{Al}=$ serum aluminum, $\mathrm{U}-\mathrm{Al}=$ urinary aluminum, $\mathrm{Al}$-months $=$ months of aluminum welding)

\begin{tabular}{|c|c|c|c|c|}
\hline Test variable & Al-Sum & S-Al & U-Al & Al-months \\
\hline Digit span forward $(\mathrm{N}=82)$ & 0.30 & 0.22 & 0.32 & 0.36 \\
\hline Digit symbol $(\mathrm{N}=82)$ & $-0.19^{\star}$ & -0.13 & $-0.23^{*}$ & -0.18 \\
\hline Bourden-Wiersna accuracy $(\mathrm{N}=81)$ & $0.24^{*}$ & $0.22^{*}$ & 0.16 & $0.25^{*}$ \\
\hline Counting backwards $(\mathrm{N}=82)$ & $-0.25^{*}$ & $-0.19^{*}$ & $-0.25^{*}$ & -0.07 \\
\hline Dual-task cancellation speed $(\mathrm{N}=81)$ & $-0.22^{*}$ & $-0.21^{*}$ & $-0.22^{*}$ & $-0.25^{*}$ \\
\hline Dual-task counting speed $(\mathrm{N}=81)$ & $-0.25^{\star}$ & $-0.20^{\star}$ & $-0.24^{*}$ & -0.13 \\
\hline Synonyms $(\mathrm{N}=78)$ & $-0.26^{*}$ & $-0.25^{*}$ & -0.10 & $-0.27^{\star \star}$ \\
\hline
\end{tabular}

${ }^{*} \mathrm{P}<0.05,{ }^{* *} \mathrm{P}<0.01$

being significant. Spikes and spike-wave complexes located bilaterally in the frontal and temporal areas were the most common epileptiform phenomena; this abnormality was detected in 5 subjects. One subject had multifocal spikes (right frontocentral, left frontotemporal, both parietooccipital areas), and 1 subject had generalized, irregular spike and wave discharges. Among the 7 subjects who had epileptiform abnormalities in their EEG recordings, the mean values of S-Al and $\mathrm{U}-\mathrm{Al}$ were 0.36 (SD $0.18) \mu \mathrm{mol} / 1$ and 6.8 (SD 3.8) $\mu \mathrm{mol} / 1$, respectively.

P3 event-related potentials. No significant correlations were observed between the $\mathrm{S}-\mathrm{Al}$ and $\mathrm{U}-\mathrm{Al}$ concentrations and the measures obtained from the P3 ERP (the amplitudes and latencies in the pitch-P3 ERP and in the duration-P3 ERP). The abnormalities in the pitch-P3 ERP were more common in the low- and high-exposure groups than in the reference group (table 9), but the trend was not significant.

\section{Dose-response relationship}

To explore the exposure-response relationship, we examined the prevalence of findings (ranging from mild to moderate) in 6 independent critical domains that had suggested an association to aluminum body burden in group comparisons. The following domains were considered: (i) symptoms: at least a mildly elevated score in reported memory and concentration difficulties or fatigue or both, (ii) visual accuracy: omissions in dot cancellation, (iii) attention: a slow performance in one of the components of the dual-task test or in both, (iv) verbal: a low score on the synonyms test, (v) visuospatial memory: a low score in memory for designs, (vi) EEG abnormality: a diffuse or epileptiform finding or both.

Previous data from normal working populations were used as a guideline when the cutting points were defined for the deviant findings in domains $\mathrm{i}-\mathrm{v}$. For the agedependent domains ( $\mathrm{i}$ and iii), age-adjusted cutting points were used. The proportion of deviant findings in each of the 6 areas varied from $15 \%$ to $20 \%$. Figure 3 shows the number of deviant findings at different levels of $\mathrm{Al}$-sum.

\section{Discussion}

It has been known for a decade that the long-term welding of aluminum with the MIG method can lead to significant absorption, as $\mathrm{S}-\mathrm{Al}$ and $\mathrm{U}-\mathrm{Al}$ levels can, in extreme cases, exceed normal values by 20 - and 100 -fold, respectively (20). Aluminum welders with about 13 years of full-time employment reported concentration difficulties and depression twice as frequently as welders of mild steel (30). Our previous study of 17 MIG welders with about 4 years of exposure and moderately raised $\mathrm{S}-\mathrm{Al}$ (mean $0.21 \mu \mathrm{mol} / \mathrm{l}$ ) and $\mathrm{U}-\mathrm{Al}($ mean $2.8 \mu \mathrm{mol} / \mathrm{l}$ ) concentrations suggested slight dose-related impairments in memory functions, learning, and attention, as well as in characteristic slowing of the EEG in the frontal region (31). A more recent study of aluminum welders whose median (maximum) blood and U-A1 levels were 0.11 (SD 1.0 ) and 0.8 (SD 9.4) $\mu \mathrm{mol} / \mathrm{l}$, respectively, showed exposure-related decrements in the motor function of the hands; the welders reported more fatigue at the time of the test (48). Although the visual interpretation of the EEG did not reveal any characteristic changes among the welders, the proportion of pathological EEG findings was double (29\%) those of the mild steel welders (13\%).

Table 9. Findings in the visual interpretation of the electroencephalography (EEG) and pitch.P3 ERPa.

\begin{tabular}{|c|c|c|c|c|c|c|c|}
\hline \multirow[t]{3}{*}{ Neurophysiological finding } & \multicolumn{7}{|c|}{ Group } \\
\hline & \multicolumn{2}{|c|}{ Referents $(\mathrm{N}=25)$} & \multicolumn{2}{|c|}{ Low exposure $(\mathrm{N}=29)$} & \multicolumn{2}{|c|}{ High exposure $(\mathrm{N}=30)$} & \multirow[t]{2}{*}{ P-value } \\
\hline & $N$ & $\%$ & $N$ & $\%$ & N & $\%$ & \\
\hline \multicolumn{8}{|l|}{ EEG } \\
\hline Diffuse abnormalities & - & 0 & 5 & 17 & 8 & 27 & 0.005 \\
\hline Epileptiform abnormalities & - & 0 & 2 & 7 & 5 & 17 & 0.020 \\
\hline \multicolumn{8}{|l|}{ Pitch-P3 ERP } \\
\hline Latency & - & 0 & 2 & 7 & 2 & 7 & 0.219 \\
\hline Amplitude & - & 0 & 1 & 3 & 2 & 7 & 0.175 \\
\hline
\end{tabular}

a Pitch-P3 ERP: P3-event-related potential = P3 ERP; pitch-P3 ERPS = the target sound stimuli differed from the standard sounds by their pitch, P3event-related potentials with pitch and duration paradigms.

b Significance tested with the exact test of trend. 


\section{Assessment of exposure}

Some of the main reasons for previous occupational studies of aluminum toxicity being inconclusive are failure to document the biologically relevant exposure dose (ie, measurement of aluminum body burden) or, when done, the fact that the increase was only modest. The present study provides data on welders with clearly higher internal aluminum loads than in any earlier corresponding occupational study.

Although not well-defined, the aluminum concentrations in serum and urine are presumed to be related to the total body burden. Among the welders of the present study the S-Al and U-Al correlated, and both also positively correlated with the exposure duration. The latter unequivocally demonstrated aluminum accumulation over time, a finding consistent with the observed slow elimination half-time of the metal in the urine of welders (at least 0.5 years) (21) and among retired flake powder workers (first 3 post-exposure years: 0.7 years, terminal 9.8 years) (25). We have previously observed (manuscript in preparation) a daily fluctuation of S-Al in welders, whereas the urinary excretion of contemporary aluminum uptake was more protracted, as also shown by Alessio and his co-workers (22) and Sjögren and his co-workers (20). To avoid this effect of daily exposure and to uncover the accumulated internal load, we used the morning sample for the S-Al analysis and the Monday morning (2 days postexposure) sample for the $\mathrm{U}-\mathrm{Al}$ analysis. In some individual cases the relationship between the S-Al and U-Al differed from that of the majority of subjects. The underlying reasons, possibly differences in serum binding or in renal excretion, are unknown. To account for such physiological variability, we used an aggregated measure of internal aluminum load (Al-sum); for several effects the Al-sum showed higher correlations than either of its components alone.

It is uncertain how good the surrogates S-Al and U$\mathrm{Al}$ are for the metal concentration in the brain, the target tissue of toxic effect. We hypothesized that they are of value since Röllin and his co-workers (49) demonstrated an almost doubling of S-Al in rabbits exposed to fine aluminum oxide dust over 5 months in a dusting chamber, and the level of aluminum in the brain was more than doubled.

\section{Psychological effects}

The subjective symptom inquiry showed exposure-related increases in memory and concentration problems, fatigue, emotional disturbances indicative of mild depression, and certain sensory and motor symptoms. Overall, the complaints associated with aluminum exposure seemed to focus on certain core symptoms rather than being expressions of a more general distress. These results tally with those of Sjögren and his co-workers (30) and White and his co-workers (26). The fact that a reversed relation between the aluminum body burden measures and subjective symptoms was found in our previous study can presumably be explained by the special characteristics of that study population: a selected group of younger, highly motivated welders with lower body burdens of aluminum coupled with a shorter exposure history (31).

The neuropsychological test battery comprised a large variety of cognitive tests, complemented by 2 psychomotor tests and a simple reaction-time test. Attention tasks ranged from a simple immediate repetition of digits to the dual-task test with high demands on attention. The verbal and visual tests for memory and learning assessed both explicit and implicit memory functioning. With this set of tests, we found a rather circumscribed exposure effect on cognitive functions. No relation to aluminum was found for verbal comprehension, as measured by the similarities subtest of WAIS, or for the verbal memory tests. Simple reaction time, psychomotor speed, and 2 visual tests also seemed to be unaffected. However, the high-exposure welders had lower performances on the synonyms test and exhibited a certain pattern in attention tests, in that they tended to be better in the digit span forward task, were equal in the Stroop task, somewhat inferior in the digit symbol task, and more so in backward counting and dot cancellation (BW). In baseline $\mathrm{BW}$, the high-exposure subjects had more omissions, and in the dual-task they were slower.

Although our data are not sufficient to conclude what functional defects in the CNS might have occurred, nonetheless, there seemed to be an effect on tasks that demanded complex attention and processing of information in the working memory system. Inferiority of the exposed groups on the synonyms test was an unexpected result,

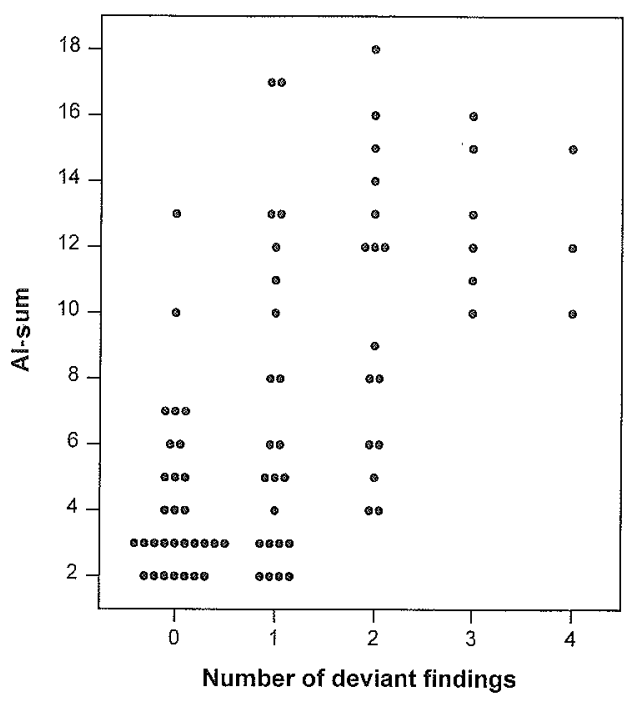

Figure 3. Relationship between the number of deviant findings and a marker of aluminum body burden (Al-sum) for 78 subjects with a complete set of data. A ball denotes the observations for one subject. 
calling for further examination of the characteristics of the task. It should be noted that, besides acquired vocabulary, the applied Finnish version requires more conceptual analysis than corresponding tests in English. Moreover, the task was time-limited, and failure may have been due to slow cognitive processing rather than to poor vocabulary. The practically equal group means for the similarities test rules out the supposition of inferior verbal abilities in the more-exposed group. The mutual correlation of these 2 verbal tests in the whole study group was low (0.26) when compared with the higher correlations $(>0.50)$ that were found in our previous populations (unpublished data on unexposed welders, lead workers, and a mixed neurological patient group). This occurrence suggests that some factor other than verbal ability and vocabulary accounted for the paradoxical finding in the synonyms test.

The detrimental effect of exposure on visual performance was restricted to a task requiring an analysis of abstract visual patterns and reproduction by recall (memory for designs) and was more marginally seen in a task requiring visuospatial analysis and reproduction of the model (block design). Tests for visual perception (embedded figures) and for incidental visual learning (recall of digit symbol pairs) seemed to be unaffected by aluminum.

A comparison of our results with those of earlier aluminum studies is problematic due to differences in the type, duration and intensity of exposure, and also the test methods applied. Qualitatively, previous studies involving foundry work and primary aluminum production (17, $26,27)$ have suggested that a long-term, low-level exposure to aluminum does not deteriorate the general cognitive level estimated by measurements of intelligence quotient, but it may affect performance in tests that are known to be sensitive to diverse disturbances in brain function, including neurotoxic damage (eg, digit symbol and block design). The results of previous studies (17, 26,31 ) have also indicated the vulnerability of memory and attention. The present study was able to reproduce the results of the memory tests only for visual memory, but indeed confirmed the effect on attention. Impaired motor function was suggested for potroom workers in a primary aluminum plant (27) and also among aluminum welders (48). In our study, no effects on psychomotor functions were noted, but it must be kept in mind that few tests were used to explore this domain. Only the symptom inquiry suggested some disturbances in motor coordination.

Among hemodialysis patients with markedly raised $\mathrm{S}-\mathrm{Al}$ (mean $2.2 \mu \mathrm{mol} / 1$ ), impaired performance was found in 6 tests measuring mainly visuospatial and visuoperceptual abilities and memory (50). Another study (51) showed aluminum-related effects on visual memory at somewhat lower S-Al levels, and also suggested adverse effects on attention and frontal lobe functioning among patients with lower verbal intelligence. Conclusions about effects specific for aluminum are limited by the underlying serious kidney disease.

\section{Neurophysiological effects}

In the visually interpreted EEG, diffuse nonspecific abnormalities were observed in the low- and high-exposure groups, whereas epileptiform abnormalities were present mainly in the high-exposure group. Increased slow activity, maximally in the frontal region, and bilateral spike and slow wave complexes are typical findings among patients with dialysis encephalopathy $(52-56)$. The severity of EEG abnormalities in clinical cases correlated with the S-Al levels, which were invariably high, the mean values in 2 patient groups were 7 and $15 \mu \mathrm{mol} / 1$ (53). In the QEEG, we observed more slow activity and less alpha activity among the subjects who had higher U-Al levels. Although this association was weak, it was in the same direction as the finding from our previous study of aluminum welders (31). Progressive slowing of the background activity in the EEG is an early finding in the dialysis encephalopathy syndrome and usually antedates neurological symptoms (55). The abnormalities observed in the present study are thus qualitatively reminiscent of those found in early stages of dialysis encephalopathy. Although the abnormalities observed in our study were very mild, they clearly raise suspicions of aluminum-related disturbances in cerebral functioning.

Since there were 3 female subjects, all belonging to the high-exposure group, it was of interest to examine their results relative to the group as a whole. In general, the mean test results of the women were rather close to those of the high-exposure group. Moreover, the women had no abnormalities in their neurophysiological recordings. Only group differences in the symptom scales, and for single symptoms, might to some extent be confounded by gender due to the high values of symptom scales for 2 female welders.

\section{Dose-response relationship}

There is no unequivocal evidence of CNS toxicity from aluminum in the occupational setting, supported by doseresponse (or dose-effect) data over a relevant range of body burdens. This is in contrast to the situation for renal patients, for whom S-Al monitoring and clinical examinations have shown that neuropsychological impairments may occur when the $\mathrm{S}-\mathrm{Al}$ concentration is about 2 $\mu \mathrm{mol} / 1$ (49), or even less among persons with lower verbal intelligence (50). The onset of the subchronic dialysis encephalopathy syndrome becomes imminent when $\mathrm{S}-\mathrm{Al}$ is in the range of $3-7 \mu \mathrm{mol} / 1$ or higher $(57,58)$. Since our study population exhibited a wide variation of $\mathrm{S}-\mathrm{Al}$ concentrations up to $1 \mu \mathrm{mol} / \mathrm{l}$ (the median in the high-exposure group being $0.5 \mu \mathrm{mol} / \mathrm{l}$ ), we felt that it was 
feasible to try to characterize the dose-response, even if only the lower end of the dose-response curve was available for the perusal of aluminum neurotoxicity.

As a measure of dose (body burden), the combined variable of $\mathrm{U}-\mathrm{Al}$ and $\mathrm{S}-\mathrm{Al}$ (Al-sum) was used. As a criterion for response, we used individual records containing deviant findings in 6 aluminum-related effect domains. The choice of the 6 critical areas was based on the results of subgroup comparisons. The criteria set for a positive response were rather mild. Moreover, the choice of the critical domains was based on our results and discretion and can, of course, be disputed. It should be noted that, with this exercise, the authors did not seek to judge the goodness of the chosen effect parameters for the characterization of aluminum toxicity, which must be validated in an independent study, but only used the effect profile to explore the dose-response.

The relationship between the number of deviant findings and aluminum body burden ( $\mathrm{Al}$-sum) for the $78 \mathrm{sub}$ jects with a complete set of data is seen in figure 3 . The data suggest that the Al-sum value of 10 is a watershed above which multiple deviant findings (a measure of adverse effect) become more apparent. The threshold of aluminum body burden implying an adverse effect thus seemed to correspond to $4-6 \mu \mathrm{mol} / \mathrm{l}$ of aluminum in urine and $0.25-0.35 \mu \mathrm{mol} / \mathrm{l}$ in serum. In view of the methodological uncertainties and the small group sizes these estimations are preliminary. However, because occupational exposures to the fumes and fine dusts of aluminum have the potential for bioaccumulation in the course of years, we recommend that due attention be given to the prevention of uptake through appropriate measures of industrial hygiene practice. Furthermore we recommend monitoring of the body burden through repeated measurements of U-Al. Successful avoidance of accumulation should dispel all major concerns about harmful health effects from exposure to aluminum.

\section{Acknowledgments}

We are greatly indebted to the management and occupational health personnel of the participating companies and to the volunteer welders for their unfailing commitment to the study. Ms O Nikulainen scheduled the examinations for the welders and supervised their daily program. Ms M Katajarinne assisted in the neuropsychological examinations. Ms R Velin and Ms S-L Vainio made the neurophysiological recordings, and Ms A Lindell performed the aluminum analyses. We also thank Dr $\mathrm{H}$ Kalska, PhD, Memory Clinic, University of Helsinki, for her valuable guidance in the selection of the neuropsychological methods used.

The study was supported by the Finnish Work Environment Fund.

\section{References}

1. Bugiani O, Ghetti B. Aluminum encephalopathy: Experimental vs human. In: DeBroe ME, Coburn LW, editors. Aluminum and renal failure. Dordrecht, Boston (London): Kluwer Academic Publishers, 1990:109-25.

2. Strong MJ, Garruto RM, Joshi JG, Mundy WR, Shafer TJ. Can the mechanisms of aluminum neurotoxicity be integrated into a unified scheme? J Toxicol Environ Health 1996; 48:599-613.

3. Yokel RA, Allen DD, Meyer JJ. Studies of aluminum neurobehavioral toxicity in the intact mammal. Cell Mol Neurobiol 1994;14:791-808.

4. Alfrey AC, Froment DC. Dialysis encephalopathy. In: DeBroe ME, Coburn LW, editors. Aluminum and renal failure. Dordrecht, Boston (London): Kluwer Academic Publishers, 1990:249-57.

5. Renard JL, Felten D, Bequet D. Post-otoneurosurgery aluminum encephalopathy. Lancet 1994;344:63-4.

6. Hantson Ph, Mahieu P, Gersdorff M, Sindic CJM, Lauwerys R. Encephalopathy with seizures after use of aluminum containing bone cement. Lancet 1994;344:1647.

7. Martyn CN, Osmond C, Edwardson JA, Barker DJP, Harris EC, Lacey RF. Geographical relationship between Alzheimer's disease and aluminum in drinking water. Lancet 1989;1:59-62.

8. Flaten TP. Geographical association between aluminum in drinking water and registered death rates with dementia (including Alzheimer's disease), Parkinson's disease and amyotrophic lateral sclerosis in Norway. Environ Geochem Health 1990;12:152-67.

9. Neri LC, Hewitt D. Geographical relation between Alzheimer's disease and aluminum in drinking water. Lancet 1991;338:390.

10. Forbes WF, Lessard S, Gentleman JF. Geochemical risk factors for mental functioning, based on the Ontario Longitudinal Study of Aging (LSA), V: comparisons of the results, relevant to aluminum water concentrations, obtained from the LSA and from death certificates mentioning dementia. Can J Aging 1995;14:642-56.

11. McLachlan DCR, Bergeron C, Smith JE, Boomer D, Rifat SL. Risk for neuropathologically confirmed Alzheimer's disease and residual aluminum in municipal drinking water employing weighted residential histories. Neurology 1996; 46:401-5.

12. Jacqmin-Gadda $\mathrm{H}$, Commenges D, Letenneur L, Dartigues JF. Silica and aluminum in drinking water and cognitive impairment in the elderly. Epidemiology 1996;7:281-5.

13. Ganroth PO. Metabolism and possible health effects of aluminum. Environ Health Perspect 1986;65:363-441.

14. Greger JL, Sutherland JE. Aluminum exposure and metabolism. Crit Rev Clin Lab Sci 1997;34:439_74.

15. Savory J, Exley C, Forbes WF, Huang Y, Joshi JG, Kruck T, et al. Can the controversy of the role of aluminum in Alzheimer's disease be resolved? what are the suggested approaches to this controversy and methodological issues to be considered? J Toxicol Environ Health 1996;48:615-35.

16. Röllin HB, Theodorou P, Cantrell AC. Biological indicators of exposure to total and respirable aluminum dust fractions in a primary aluminum smelter. Occup Environ Med 1996; 53:417-21.

17. Hošovski E, Mastelica Z, Šunderic D, Radulovic D. Mental abilities of workers exposed to aluminum. Med Lav 1990; 
81:119-23.

18. Röllin HB, Theodorou $\mathrm{P}$, Kilroe-Smith TA. The effect of exposure to aluminum on concentrations of essential metals in serum of foundry workers. Br J Ind Med 1991;48:243—6.

19. Letzel S, Schaller KH, Angerer J, Drexler H, Weber A, Schmid K, et al. Biological monitoring of occupational aluminum powder exposure. Occup Hyg 1996:3:271—80.

20. Sjögren B, Lidums V, Håkansson M, Hedström L. Exposure and urinary excretion of aluminum during welding. Scand $\mathrm{J}$ Work Environ Health 1985;11:39-43.

21. Sjögren B, Elinder C-G, Lidums V, Chang G. Uptake and urinary excretion of aluminum among welders. Int Arch Occup Environ Health 1988;60:77-9.

22. Alessio L, Apostoli P, Ferioli A, Di Sipio I, Mussi I, Rigosa $\mathrm{C}$, et al. Behaviour of biological indicators of internal dose and some neuro-endocrine tests in aluminum workers. Med Lav 1989;80:290-300

23. Sjögren B, Lundberg I, Lidums V. Aluminum in the blood and urine of industrially exposed workers. Br J Ind Med 1983;40:301-4.

24. McLaughlin AIG, Kazantzis G, King E, Teare D, Porter RJ, Owen R. Pulmonary fibrosis and encephalopathy associated with the inhalation of aluminum dust. Br J Ind Med 1962; 19:253-63.

25. Sjögren B, Ljunggren KG, Almkvist O, Frech W, Basun H. A follow-up study of five cases of aluminosis. Int Arch Occup Environ Health 1996;68:161-4.

26. White DM, Longstreth WT, Rosenstock L, Claypoole KHJ, Brodkin CA, Townes BD. Neurologic syndrome in 25 workers from an aluminum smelting plant. Arch Intern Med 1992;152:1443-48.

27. Bast-Pettersen R, Drablos PA, Goffeng LO, Thomassen Y, Torres CG. Neuropsychological deficit among elderly workers in aluminum production. Am J Ind Med 1994;25:649-62.

28. Rifat SL, Eastwood MR, Crapper McLachlan DR, Corey PN. Effect of exposure of miners to aluminum powder. Lancet 1990;336:1162-5.

29. Salib E, Hillier V. A case-control study of Alzheimer's disease and aluminum occupation. Br J Psychol 1996;168:244 9.

30. Sjögren B, Gustavsson P, Hogstedt C. Neuropsychiatric symptoms among welders exposed to neurotoxic metals. Br J Ind Med 1990;47:704-7.

31. Hänninen H, Matikainen E, Kovala T, Valkonen S, Riihimäki $V$. Internal load of aluminum and the central nervous system function of aluminum welders. Scand J Work Environ Health 1994;20:279-85.

32. Gamberale F, Iregren A, Kjellberg A. SPES: the computerized Swedish Performance Evaluation Test. Stockholm: Arbetarskyddsverket, 1989. Arbete och Hälsa 6.

33. Hänninen $\mathrm{H}$, Lindström K. Neurobehavioral test battery. Helsinki: Työterveyslaitos, 1989.

34. Wechsler D. Wechsler adult intelligence scale. WAIS manual. Helsinki: Psykologien kustannus Oy, 1992.

35. Wechsler D. Wechsler adult intelligence scale. WAIS manual. Helsinki: Psykologien kustannus Oy, 1971.

36. Stroop JR. Studies of interference on serial verbal reactions. J Exp Psychol 1935;18:643-62.

37. Vilkki J, Virtanen S, Surma-aho O, Servo A. Dual task performance after focal cerebral lesions and closed head injury. Neuropsychologia 1996;34:1051-6.

38. Valciukas JA, Singer RM. The embedded figures test in epidemiological studies of environmental neurotoxic agents. New
York (NY): Environmental Sciences Laboratory, Mount Sinai School of Medicine, 1979.

39. Wechsler D. Wechsler memory scale. WMS manual. 3rd ed. Helsinki: Psykologien kustannus Oy, 1986.

40. Lezak MD. Neuropsychological assessment. 3rd Ed. New York (NY): Oxford University Press, 1995.

41. Christensen A-L. Luria's neuropsychological investigation. Copenhagen: Munksgaard, 1974.

42. Valkonen S, Aitio A. Analysis of aluminum in serum and urine for the biomonitoring of occupational exposure. Sci Total Environ 1997;199:103-10.

43. Tukey JW. Allowances for various types of error rates. Presented at an IMS meeting, Chicago (IL), 1952.

44. Kramer CY. Extension of multiple range tests to group means with unequal numbers of replications. Biometrics 1956:30710.

45. Margolin BH. Test for trend in proportions. In: Kotz S, Johnson NL, editors. Encyclopedia of statistical science, vol 9. New York (NY): Wiley, 1988:334—6.

46. Agresti A. Categorical data analysis. New York (NY): Wiley, 1990.

47. Mehta CR, Patel NR. A network algorithm for performing Fisher's exact test in rxc contingency tables. J Am Stat Assoc 1983:78:427-34.

48. Sjögren B, Iregren A, Frech W, Hagman M, Johansson L, Tesarz M, et al. Effects on nervous system among welders exposed to aluminium and manganese. Occup Env Med 1996:53:32-40.

49. Röllin HB, Theodorou P, Kilroe-Smith TA. Deposition of aluminium in tissues of rabbits exposed to inhalation of low concentrations of $\mathrm{Al}_{2} \mathrm{O}_{3}$ dust. Br J Ind Med 1991;48:389-91.

50. Altmann P, Hamon C, Blair J, Dhanesha U, Cunningham J, Marsh F. Disturbance of cerebral functioning by aluminium in haemodialysis patients without overt aluminium toxicity. Lancet 1989;2:7-12.

51. Bolla KI, Briefel G, Spector D, Schwartz BS, Wieler L, Herron J, et al. Neurocognitive effects of aluminum. Arch Neurol 1992;49:1021-6.

52. Hughes JR, Schreeder MT. EEG in dialysis encephalopathy. Neurology 1980;30:1148—54

53. Ladurner G, Wawschinek O, Pogglitsch H, Petek W, Urlesberger $\mathrm{H}$, Holzer $\mathrm{H}$. Neurophysiological findings and serum aluminum in dialysis encephalopathy. Eur Neurol $1982 ; 21: 335-9$.

54. Lederman RJ, Henry CE. Progressive dialysis encephalopathy. Ann Neurol 1978;4:199-204.

55. Mahurkar SD, Smith EC, Mamdani BH, Dunea G. Dialysis dementia - the Chicago experience. J Dialysis 1978;2:44758.

56. Rovelli E, Luciani L, Pagani C, Albonico C, Colleoni C, D'Amigo G. Correlation between serum aluminum concentration and signs of encephalopathy in a large population of patients dialyzed with aluminum-free fluids. Clin Nephrol $1988 ; 26: 294-8$

57. Cannata Andia JB, Diaz Lopez JB. The diagnosis of aluminium toxicity. In: DeBroe ME, Coburn LW, editors. Aluminum and renal failure. Dordrecht, Boston (London): Kluwer Academic Publishers, 1990:289-308.

58. Alfrey AC. Aluminum and renal disease. In: Bourke E, Mallick NP, Pollak VE, editors. Moving points in nephrology. Basel (Germany): Karger, 1993:110—24.

Received for publication: 28 May 1999 